\title{
Improvement in the Design \& Manufacturing of Twin Worm Self Locking Technique and applications
}

\author{
Prof. P.B. Kadam ${ }^{1}$, Prof. M.R. Todkar ${ }^{2}$ \\ ${ }^{1}$ Assistant Professor, Mechanical Engineering Department, T.K.I.E.T.Warananagar, Tal. Panhala, Dist. Kolhapur, India. \\ ${ }^{2}$ Assistant Professor, Mechanical Engineering Department, T.K.I.E.T.Warananagar, Tal. Panhala, Dist. Kolhapur, India.
}

\begin{abstract}
In most of the gear drives, when the driving torque is suddenly reduced as a result of power off, torsional vibration, power outage or any mechanical failure at the transmission input side, then gears will be rotating either in the same direction driven by the system inertia, or in the opposite direction driven by the resistant output load due to gravity, spring load, etc. The latter condition is known as back driving. However, there are also solutions in gear transmission that prevent inertial motion or back driving using self-locking gears without any additional devices.

The term self locking as applied to gear systems denotes a drive which gives the input gear the freedom to rotate the output gear in either directions but the output gear locks with input when an outside torque attempts to rotate the output in either direction.Worm gears are one of the few gear systems that can be made self locking, but at the total of efficiency, they rarely exceed $40 \%$ efficiency, when made self locking. The experiment is carried in the laboratory with sufficient small prototype model.
\end{abstract}

Keywords:- Self Locking; Efficiency; Input shaft; Output shaft.

\section{Introduction}

This innovation in gearing is a combination of two worm screws that gives self locking characteristics or to operate as fast acting brake when power is shut off.

The Mating worm self-locking system is a simple dual worm system that not only provided self locking with maximum efficiency, but also exhibited a new phenomenon called deceleration locking._The mating worm gear drive is quite simply constructed, two threaded rods, or worm screws are meshed together. Each worm is wound in a different direction and has a different pitch angle. For proper mesh the worm axes are not parallel but slightly skewed. But by selecting proper and different pitch angles, the drive exhibit self locking or combination of self locking and deceleration locking as desired. Some of the solutions for these, there is no principle or accuracy in manufacturing these gears but for solution on that the twin worm gear drive is quite simply constructed two thread rod or worm screw meshed together. Each worm is wound in different direction and has different pitch angle for proper mesh the worm axes are not parallel but slightly screwed. By selecting proper and different pitch angle the drive wheel exhibits self locking or combination of self locking and deceleration on desired. The term self locking as applied to gear systems denotes a drive which gives the input gear the freedom to rotate the output gear in either directions but the output gear locks with input when an outside torque attempts to rotate the output in either direction. This characteristic is often shown after by designers who want to be sure that the loads on the output side of the system cannot affect the position of the gears. Worm gears are one of the few gear systems that can be made self locking, but at the total of efficiency, they rarely exceed $40 \%$ efficiency, when made self locking. 
IOSR Journal of Engineering

May. 2012, Vol. 2(5) pp: 1224-1233

\section{TWIN WORM GEAR SELF LOCKING SYSTEM}

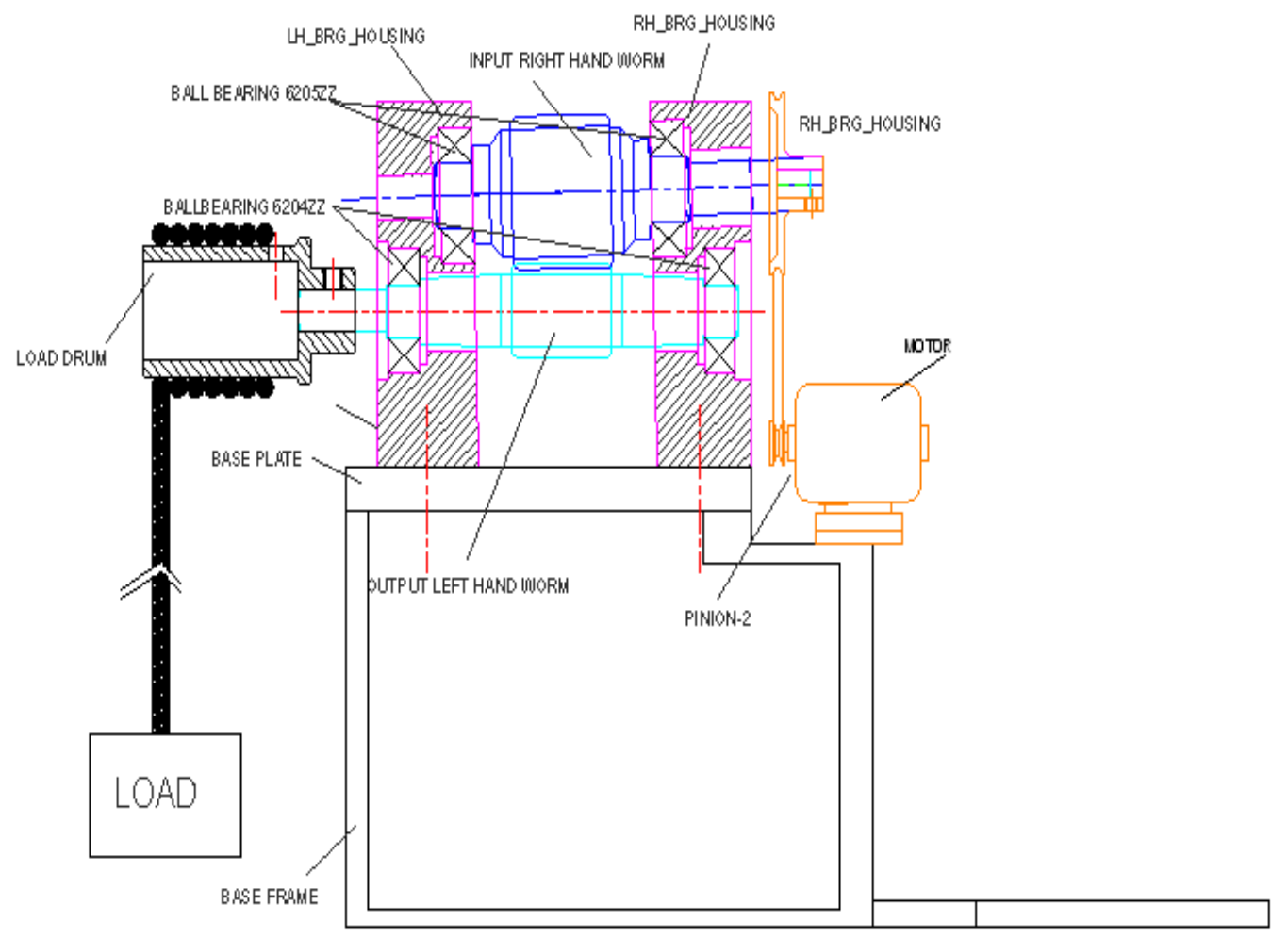

Fig. 1.1 Twin worm gear self locking system

\section{Design Procedure}

System design mainly concerns with various physical constrains, deciding basic working principle, space requirements, arrangements of various components etc.

Following parameters are looked upon in system design.

1. Selection of system based on physical constraints. The mechanical design has direct norms with the system design hence system is designed such that distinctions and dimensions thus obtained in mechanical design can be well fitted in to it.

2. Arrangement of various components made simple to utilize every possible space.

3. Ease of maintenance and servicing achieved by means of simplified layout that enables quick decision assembly of components.

4. Scope of future improvement.

\subsection{Approach to Mechanical Design of 'Twin Worm System'}

Selection of appropriate material .

- Assuming an appropriate dimension as per system design.

- Design check for failure of component under any possible system of forces. 
Our present model is an demonstrative set up in order to show the motion and power transmission capabilities of the proposed 'Twin Worm System'

Thus selecting a drive motor as follows,

Transmission of power to the input shaft is done by means of motor of the following specifications

\subsubsection{Motor:}

Electric motor of following specification is used as the source of power in drive ;

230 volt, $50 \mathrm{~Hz}, 0.5 \mathrm{Amp}$

Power $=50$ watt $(1 / 15 \mathrm{HP})$

Speed $=0$ to $9000 \mathrm{rpm}$

TEFC construction

Commutator Motor.

Input Torque at motor $=60 \times 50 /(2 \times \Pi \times 400)=1.19 \mathrm{~N}-\mathrm{m}$

Reduction ratio of belt drive $=5$

Tdesign $=5.96 \mathrm{~N}-\mathrm{m}$

\subsubsection{Design of Input Shaft:}

The right hand worm gear is the input gear of the system, it has worm threads of 2 module which are machined with right hand of operation with helix angle of 2 degrees. The root clearance is appropriately provided, as well as the pressure angle is maintained at 14.5 degree .It is mounted at an angle of 1.5 degrees to the horizontal, this angle is the opening angle between the two worm shafts. The shaft is held between two medium duty ball bearings i.e.single row deep groove ball bearings with metallic seals at either end.

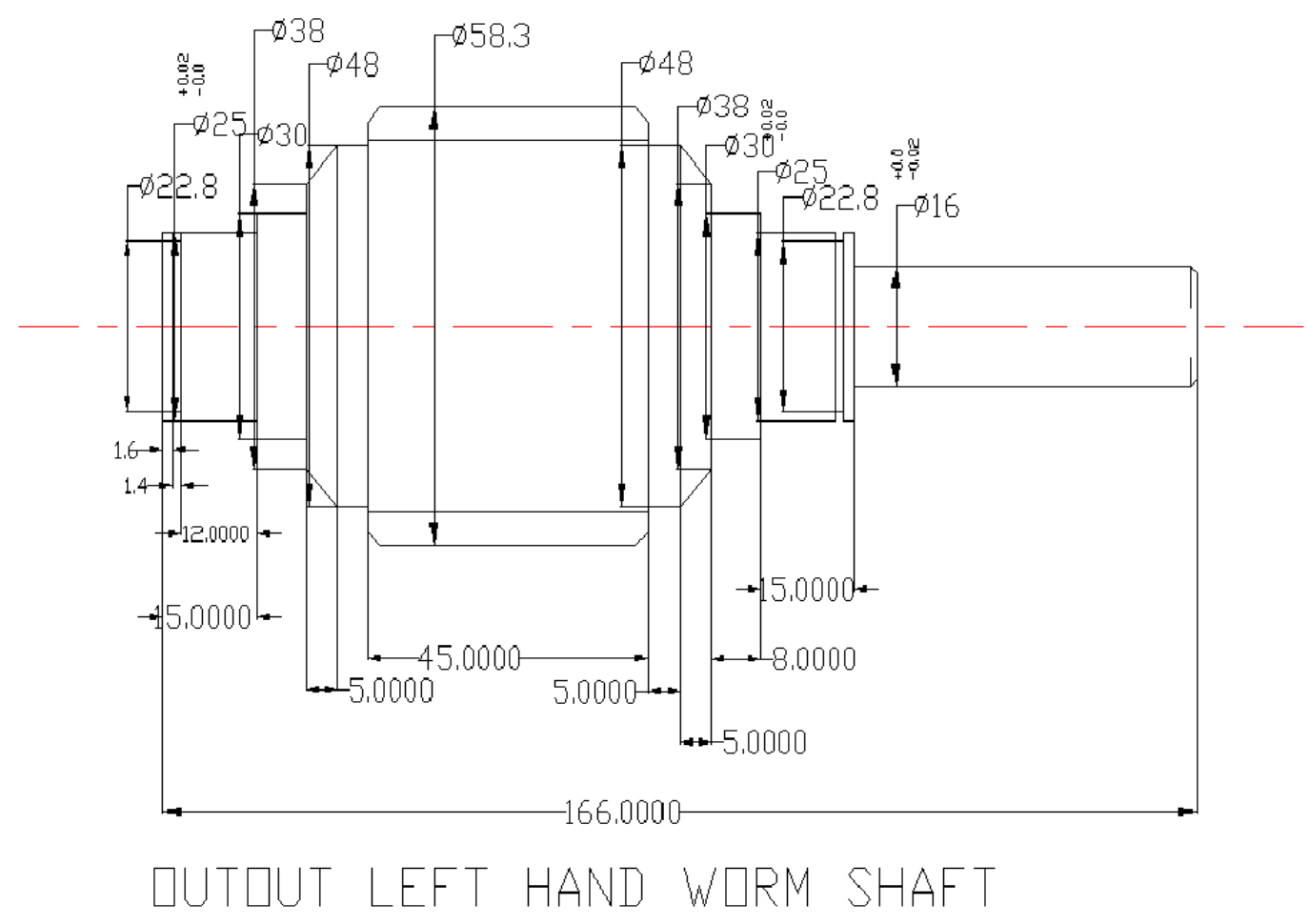

Figure 2.1 Design of Input shaft 


\subsubsection{ASME Code for Design of Input shaft}

Since the loads on most shafts in connected machinery are not constant, it is necessary to make proper allowance for the harmful effects of load fluctuations

According to ASME code permissible values of shear stress may be calculated form various relation.

$$
\begin{aligned}
\tau_{\max }=0.18 & \times \text { Sut } \\
& =0.18 \times 800 \\
& =144 \mathrm{~N} / \mathrm{mm}^{2}
\end{aligned}
$$

OR

$\tau_{\max }=0.3 \times$ Syt

$$
=0.3 \times 680=204 \mathrm{~N} / \mathrm{mm}^{2}
$$

Considering minimum of the above values;

$$
\Rightarrow \tau_{\max }=144 \mathrm{~N} / \mathrm{mm}^{2}
$$

This is the allowable value of shear stress that can be induced in the shaft material for safe operation

In selection of ball bearing the main governing factor is the system design of the drive i.e. the size of the ball bearing is of major importance hence we shall first select an appropriate ball bearing first select an appropriate ball bearing first taking into consideration convenience of mounting the planetary pins and then we shall check for the actual life of ball bearing .

$\mathrm{P}=\mathrm{X} \mathrm{Fr}+\mathrm{Yfa}$.

Where;

$\mathrm{P}=$ Equivalent dynamic load, $(\mathrm{N})$

$\mathrm{X}=$ Radial load constant

$\mathrm{Fr}=$ Radial load $(\mathrm{H})$

$\mathrm{Y}=$ Axial load contact

$\mathrm{Fa}=$ Axial load $(\mathrm{N})$

In our case;

Radial load $\mathrm{F}_{\mathrm{R}} \quad=\mathrm{RA}$

Axial load $\left(\mathrm{F}_{\mathrm{a}}\right)$

$$
=135 \mathrm{~N}
$$

$\mathrm{F}_{\mathrm{a}}=0$

Now, $\mathrm{P} \times \mathrm{Fr}=1 \times 135$ $=135$

$\mathrm{L}=(\mathrm{C} / \mathrm{P})^{\mathrm{p}}$

here, $\mathrm{p}=3$, for single row ball bearings

$\mathrm{L}=60 \mathrm{n} \mathrm{L} \mathrm{h} / 10^{6}$

$=60 \times 1000 \times 4000 / 10^{6}$

$=240 \mathrm{mrev}$

Therefor, $\quad \mathrm{C}=842.68 \mathrm{~N}$

As required dynamic of bearing is less than the rated dynamic capacity of bearing.

So bearing is safe. 


\subsubsection{Design of Output Shaft:}

The left hand worm gear is the output gear of the system, it has worm threads of 2 module which are machined with left hand of operation with helix angle of 5 degrees. The root clearance is appropriately provided, as well as the pressure angle is maintained at 14.5 degrees. The shaft is held between two medium duty ball bearings $6204 \mathrm{zz}$ ie, single row deep groove ball bearings with metallic seals at either end and it is placed parallel to the horizontal.

In selection of ball bearing the main governing factor is the system design of the drive i.e. the size of the ball bearing is of major importance ; hence we shall first select an appropriate ball bearing first select an appropriate ball bearing first taking into consideration convenience of mounting the planetary pins and then we shall check for the actual life of ball bearing .

$\mathrm{P}=\mathrm{X} \mathrm{Fr}+\mathrm{Yfa}$.

Where ;

$\mathrm{P}=$ Equivalent dynamic load ,(N)

$\mathrm{X}=$ Radial load constant

$\mathrm{Fr}=$ Radial $\operatorname{load}(\mathrm{H})$

$\mathrm{Y}=$ Axial load contact

$\mathrm{Fa}=$ Axial load $(\mathrm{N})$

In our case;

Radial load $\mathrm{F}_{\mathrm{R}} \quad=\mathrm{RA}$

Axial load $\left(\mathrm{F}_{\mathrm{a}}\right)$

$$
=100 \mathrm{~N}
$$

$\mathrm{F}_{\mathrm{a}}=0$

Now, $\mathrm{P} \times \mathrm{Fr}=1 \times 100$

$$
=100
$$

But, $\mathrm{L}=(\mathrm{C} / \mathrm{P})^{\mathrm{p}}$

here, $\mathrm{p}=3$, for single row ball bearings,

$$
\begin{aligned}
\mathrm{L} & =60 \mathrm{n} \mathrm{L} \mathrm{h} / 10^{6} \\
& =60 \times 1000 \times 4000 / 10^{6} \\
& =240 \mathrm{mrev}
\end{aligned}
$$

Therefor, $\mathrm{C}=464.1 \mathrm{~N}$

As required dynamic of bearing is less than the rated dynamic capacity of bearing.

So bearing is safe. 


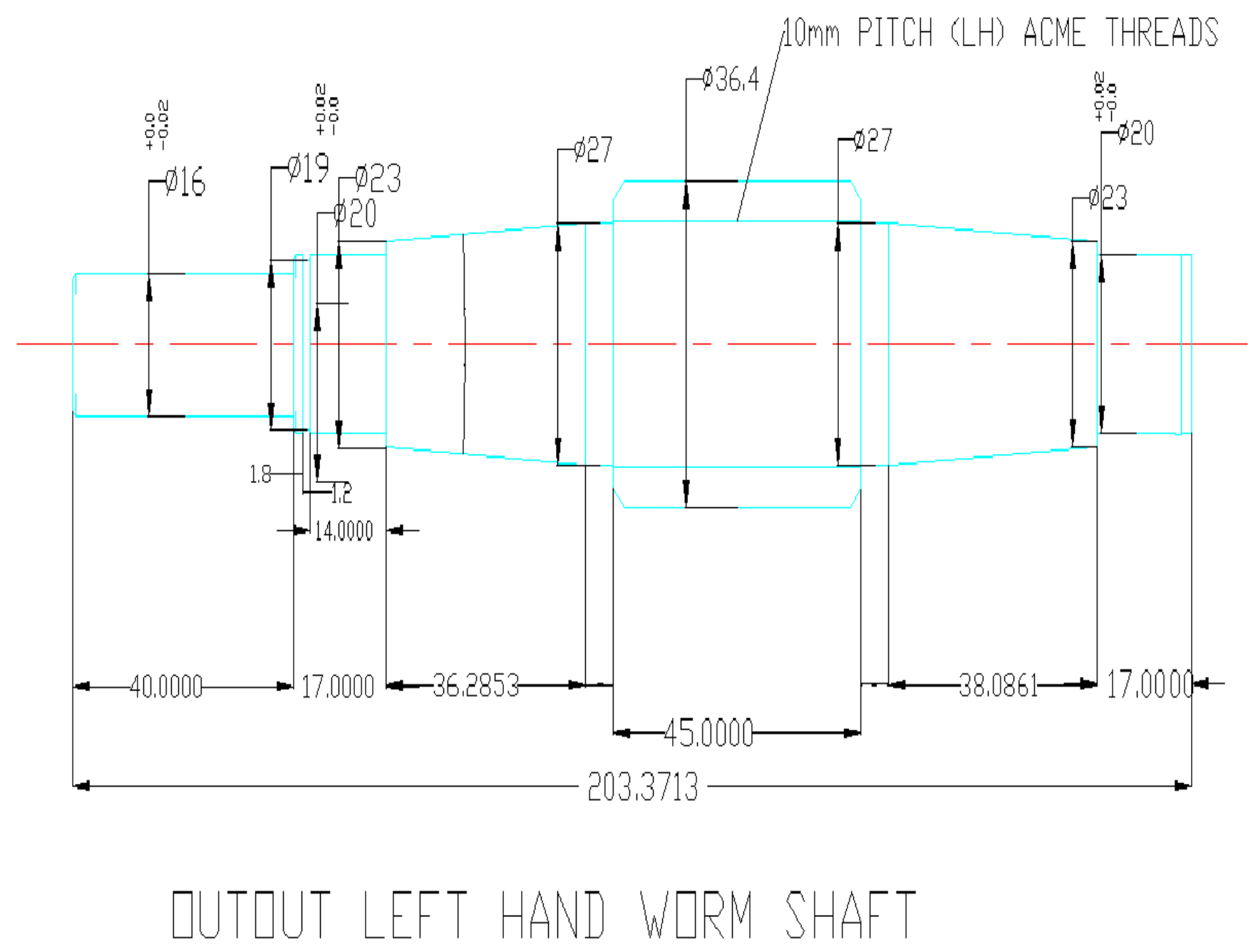

Figure 2.2 Design of Output shaft

\subsubsection{ASME codes for Design of Output shaft}

Since the loads on most shafts in connected machinery are not constant, it is necessary to make proper allowance for the harmful effects of load fluctuations

Then shear stress calculated form various relation.

$$
\begin{aligned}
\tau_{\max } & =0.18 \times \text { Sut } \\
& =0.18 \times 650 \\
& =117 \mathrm{~N} / \mathrm{mm}^{2}
\end{aligned}
$$

OR

$$
\begin{aligned}
\tau_{\max } & =0.3 \times \mathrm{Syt} \\
& =0.3 \times 480 \\
& =144 \mathrm{~N} / \mathrm{mm}^{2}
\end{aligned}
$$

considering minimum of the above values ;

$\Rightarrow \tau_{\max }=117 \mathrm{~N} / \mathrm{mm}^{2}$ 
Shaft is provided with notch for locking this will reduce its strength. Hence reducing above value of allowable stress by $25 \%$

$$
\Rightarrow \quad \tau_{\max }=87.75 \mathrm{~N} / \mathrm{mm}^{2}
$$

This is the allowable value of shear stress that can be induced in the shaft material for safe operation.

$\mathrm{T}=5.96 \times 10^{3} \mathrm{~N}-\mathrm{mm}$

Assuming 25\% overload.

$\Rightarrow \mathrm{T}$ design $=1.25 \times \mathrm{T}$

$$
=7.46 \times 10^{3}
$$

\subsubsection{Check for Torsional Shear failure of shaft:}

Assuming minimum section diameter on input shaft $=16 \mathrm{~mm}$

$\Rightarrow \mathrm{d}=20 \mathrm{~mm}$

$\mathrm{Td}=\pi / 20 \times \tau_{\text {act }} \times \mathrm{d}^{3}$

$$
\begin{aligned}
& \Rightarrow \tau_{\mathrm{act}}= \frac{20 \times \mathrm{Td}}{\pi \times \mathrm{d}^{3}} \\
&= \frac{20 \times 7.46 \times 10^{3}}{\pi \times(16)^{3}} \\
& \Rightarrow \tau_{\text {act }}=49.39 / \mathrm{mm}^{2}
\end{aligned}
$$

As, $\quad \tau_{\text {act }}<\tau_{\text {th }}$

$\Rightarrow \mathrm{I} / \mathrm{P}$ shaft is safe under tensile load.

\subsubsection{Design of load drum hub:}

Load drum hub can be considered to be a hollow shaft subjected to torsional load.

As Per ASME Code;

$\Rightarrow \tau_{\max }=108 \mathrm{~N} / \mathrm{mm}^{2}$

Check for torsional shear failure:-

$$
\begin{aligned}
& \mathrm{T}=\pi \frac{\mathrm{x} \tau}{16} \text { act_ } \_\left(\frac{\mathrm{Do}^{4}-\mathrm{Di}^{4}}{\mathrm{Do}}\right. \\
& 7.46 \times 10^{3}=\pi \frac{\mathrm{x} \tau_{\text {act }}}{16} \times\left(\frac{32^{4}-16^{4}}{32}\right. \\
& \Rightarrow \tau{ }_{\text {act }}=1.237 \mathrm{~N} / \mathrm{mm}^{2} \\
& \text { As; } \tau_{\text {act }}<\tau_{\text {all }}
\end{aligned}
$$

$\Rightarrow$ Hub is safe under torsional load.

\subsubsection{Design of Screw:}


$\mathrm{d}=$ Nominal /outer diameter $(\mathrm{mm})=32.36 \mathrm{~mm}$

$\mathrm{dc}=$ core $/$ inner diameter $(\mathrm{mm})=22.36 \mathrm{~mm}$

$\mathrm{dm}=$ mean diameter $(\mathrm{mm})=19 \mathrm{~mm}$

$\mathrm{M}_{\mathrm{t}}=\mathrm{W} \mathrm{x}(\mathrm{dm} / 2) \tan (\varnothing+\propto)$

Where, $\mathrm{W}=$ Axial load

$\varnothing=$ friction angle

$\propto=$ Helix angle

\subsubsection{Helix angle:}

$$
\tan \propto=\frac{\mathrm{L}}{\pi \mathrm{dm}}
$$

For the single start sq. thread lead is same as pitch $=10$

$$
\begin{aligned}
\tan \propto & =10 / \pi \times 27.36 \\
\propto & =6.63
\end{aligned}
$$

\subsubsection{Friction Angle:}

Coefficient of friction under different conditions like average quality of material \& workmanship \& average running conditions average coefficient of friction taken for starting is 0.18 and for running 0.13 .

$$
\begin{aligned}
& \Rightarrow \\
& \mu=\tan \varnothing \\
& 0.18=\tan \varnothing \\
& \Rightarrow \varnothing=10.2
\end{aligned}
$$

Assuming that load of $800 \mathrm{~kg}$ is carried by the drum of $120 \mathrm{~mm}$ diameter, then the resultant Torque,

$$
\mathrm{T}=8000 \mathrm{X} 60=480000 \mathrm{~N}-\mathrm{mm}
$$

$\mathrm{M}_{\mathrm{t}}=\mathrm{WX} 27.32 / 2 \times \tan (10.2+6.63)$

$\mathrm{M}_{\mathrm{t}}=4.13$ X W N-mm --------(B)

Equating (A) \& (B)

$\mathrm{W}=116.22 \mathrm{KN}$.

\section{Nomenclature}

$\mathrm{P}=\mathrm{X} \mathrm{Fr}+\mathrm{Yfa}$.

Where;

$\mathrm{P}=$ Equivalent dynamic load, $(\mathrm{N})$

$\mathrm{X}=$ Radial load constant

$\mathrm{Fr}=$ Radial load $(\mathrm{H})$

$\mathrm{Y}=$ Axial load contact

$\mathrm{Fa}=$ Axial load $(\mathrm{N})$

$\mathrm{d}=$ Nominal /outer diameter $(\mathrm{mm})=32.36 \mathrm{~mm}$

$\mathrm{dc}=$ core $/$ inner diameter $(\mathrm{mm})=22.36 \mathrm{~mm}$

$\mathrm{dm}=$ mean diameter $(\mathrm{mm})=19 \mathrm{~mm}$

$\mathrm{M}_{\mathrm{t}}=\mathrm{W} \times(\mathrm{dm} / 2) \tan (\varnothing+\propto)$ 
Where, $\mathrm{W}=$ Axial load

$\varnothing=$ friction angle

$\propto=$ Helix angle

\subsection{Result Table:}

\begin{tabular}{|c|c|c|c|c|c|}
\hline \multirow{2}{*}{ Sr. No. } & \multicolumn{2}{|c|}{ Loading } & \multicolumn{2}{c|}{ Unloading } & \multirow{2}{*}{ Mean Speed } \\
\cline { 2 - 5 } & Weight $(\mathrm{gm})$ & Speed $(\mathrm{rpm})$ & Weight $(\mathrm{gm})$ & Speed $(\mathrm{rpm})$ & \\
\hline 1. & 500 & 856 & 500 & 862 & 858 \\
\hline 2. & 600 & 826 & 600 & 828 & 827 \\
\hline 3. & 700 & 682 & 700 & 686 & 684 \\
\hline 4. & 800 & 643 & 800 & 647 & 645 \\
\hline 5. & 900 & 614 & 900 & 616 & 615 \\
\hline 6. & 1000 & 579 & 1000 & 583 & 582 \\
\hline
\end{tabular}

Table 3.1. Measured different speed for different weight

\section{Verification and Validation}

The results are implemented highly loaded self locking system. The efficiency $89 \%$ is getting experimentally for light model considering different losses. On the basis of this efficiency other heavy twin worm self locking system can be designed also implemented in order to optimization of design and enhance the life of the product which again can be a different project altogether.

\section{Results and Discussion:}

1) Average Speed: $N=N_{1}+N_{2} / 2$

$$
\begin{aligned}
& =826+828 / 2 \\
& =827
\end{aligned}
$$

2) Output Torque:-

$$
\begin{aligned}
\mathrm{T}_{\mathrm{dp}} & =\text { Weight in pan } \times \text { Radius of Pulley } \\
& =(0.6 \times 9.81) \times 12.5 \\
& =73.575 \text { N.mm } \\
\mathrm{T}_{\mathrm{dp}} & =0.0737575 \mathrm{~N} . \mathrm{mm}
\end{aligned}
$$

3) Input Power:- $\left(\mathrm{P}_{\mathrm{i} / \mathrm{p}}\right)$

$$
\begin{aligned}
\mathrm{P}_{\mathrm{i} / \mathrm{p}} & =2 \pi \mathrm{N} \mathrm{T}_{\mathrm{i} / \mathrm{p}} / 60 \\
& =2 \times \pi \times 827 \times 0.08 / 60 \\
\mathrm{P}_{\mathrm{i} / \mathrm{p}} & =6.92 \mathrm{watt}
\end{aligned}
$$

4) OutPut Power:- $\left(\mathrm{P}_{\mathrm{o} / \mathrm{p}}\right)$

$$
\begin{aligned}
\mathrm{P}_{\mathrm{o} / \mathrm{p}} & =2 \pi \mathrm{NT}_{\mathrm{o} / \mathrm{p}} / 60 \\
& =2 \times \pi \times 827 \times 0.0737575 / 60 \\
\mathrm{P}_{\mathrm{o} / \mathrm{p}} & =6.18 \text { watt }
\end{aligned}
$$




\section{5) Efficiency:-}

$$
\begin{aligned}
& =\text { Output Power } / \text { Input Power } \\
& =6.18 \times 100 / 6.92 \\
& =89.30 \%
\end{aligned}
$$

$\Rightarrow$ Efficiency of transmission of orbital mechanism at 90 degree $=89.30 \%$

\section{Conclusion}

Efficiency of self locking gear box from patent paper by Devid W. Pessen gives up to $92 \%$ we have to calculate it from the actually by,

Efficiency:-

$$
=\frac{\text { output power }}{\text { Input power }}
$$

is $89.30 \%$. Which it gives to nearer to theoretical efficiency.

Also, twin worm self locking system reduces the hole gear box of the lifting mechanism which, reduces the cost and total size. Therefore it is very useful in lift and also in industrial application.

\section{Acknowledgement}

I am thankful to my Co-author Prof. M.R.Todkar, Mechanical Engineering Dept., TKIET, Warananagar,for their encouragement and support to carry out this work.

\section{References}

[1] Quick release mechanism for self-locking mating worms-Devid pessen.

[2] Design of machine elements -V B Bhandari(Third Edition)"Tata McGraw Hill Education Private Limited"

[3] ASME Codes \& Standards.

[4] M.D.-P.S.G.(Sixth Edition) )"Tata McGraw Hill Education Private Limited"

[5] Popper ,J.B., Cooperating Wedges including mating worms, US Patent 2973660, 1961.

[6] 11. Leonesio M, Bianchi G, Manara P (2007) A general approach for self-locking analysis in closed kinematic chains. In: 12th IFToMM world congress, Besançon (France), June 18-21

[7] 12. Leonesio M, Bianchi G (2009) Self-locking analysis in closed kinematic chains.Mech Mach Theory 2052. doi:10.1016/j.mechmachtheory.2009.05.005

[8] Artobolevskii, I.I., Teoriya mekhanizmov i mashin (Theory of Mechanisms and Machines), Moscow: Nauka, 1975.

[9] Kargin, P.A., Design and Testing of Self_Braking Gear Transmissions, Vestn. Mashinostr., 2008, no. 12, pp. 3-6. 